\title{
Review of Fundamental Properties of Gas Hydrates: Breakout Sessions of the International Workshop on Methane Hydrate Research and Development
}

\author{
Tsutomu Uchida ${ }^{1, *}$, Bjørn Kvamme ${ }^{2}$, Richard B. Coffin ${ }^{3}$, Norio Tenma ${ }^{4}$, Ai Oyama ${ }^{5}$ \\ and Stephen M. Masutani ${ }^{5}$ \\ 1 Faculty of Engineering, Hokkaido University, Sapporo 060-8628, Hokkaido, Japan \\ 2 Department of Physics and Technology, University of Bergen, 5020 Bergen, Norway; bjorn.kvamme@uib.no \\ 3 Texas A\&M University-Corpus Christi, Corpus Christi, TX 78412, USA; richard.coffin@tamucc.edu \\ 4 Methane Hydrate Project Unit, Research Institute of Energy Frontier, Department of Energy and \\ Environment, National Institute of Advanced Industrial Science and Technologies (AIST), Tsukuba 305-8569, \\ Ibaraki, Japan; tenma-n@aist.go.jp \\ 5 Hawaii Natural Energy Institute, University of Hawaii, Honolulu, HI 96822, USA; \\ aioyama@hawaii.edu (A.O.); stephenm@hawaii.edu (S.M.M.) \\ * Correspondence: t-uchida@eng.hokudai.ac.jp; Tel.: +81-11-706-6635
}

Academic Editor: Enrico Sciubba

Received: 29 March 2017; Accepted: 18 April 2017; Published: 25 May 2017

\begin{abstract}
The International Workshop on Methane Hydrate (MH) Research and Development (the Fiery Ice Workshop) began in 2001 with the goal of promoting laboratory and field research collaborations and providing a forum to share new knowledge on $\mathrm{MH}$ pertaining to coastal stability, climate change, and energy. Ten workshops have been held over the past 15 years in different countries. Each workshop has included presentations on national programs and policy areas, and new research, along with breakout sessions that focused on current key topics. Two or three concurrent breakout sessions were conducted twice during each workshop. In this paper, we review the breakout sessions on hydrate fundamental properties with the goal of identifying the major accomplishments and changes in hydrate science and engineering related to determining fundamental $\mathrm{MH}$ properties over the past 15 years.
\end{abstract}

Keywords: fundamental property; laboratory study; modelling; industrial application

\section{Introduction}

Breakout sessions of the Fiery Ice Workshop are unique in that workshop attendees from diverse backgrounds, such as academics, representatives from industry, and policy makers, assemble according to their interests to discuss and debate the state-of-the-art, challenges, and/or the future plans for specific topics. Five to six areas are usually discussed in the breakout sessions at each workshop. Two or three sessions are held in parallel, and each session lasts for approximately 2 to $3 \mathrm{~h}$ in the form of round table discussions. The chairpersons (i.e., the session Chair and Rapporteur) are selected from attendees of the workshop to lead and moderate the discussions.

In this paper, we review the breakout sessions on fundamental properties of gas hydrates over the past ten workshops to document accomplishments and changes in research interests over this period.

Table 1 lists the breakout sessions on fundamental properties of gas hydrates, chair persons, and rapporteurs for the past ten workshops. At some workshops, more than one session was designated to discuss hydrate fundamental properties. At the latest Fiery Ice Workshop in 2016, we discussed the 15 years of progress and future directions in this area. 
Table 1. Title and chairs of breakout sessions on the topics of the fundamental properties of gas hydrates in each Fiery Ice Workshop. MH: Methane Hydrate.

\begin{tabular}{|c|c|c|c|c|c|}
\hline \multirow{2}{*}{ Number } & \multirow{2}{*}{ Venue } & \multirow{2}{*}{ Date } & \multicolumn{3}{|c|}{ Session Title } \\
\hline & & & \multicolumn{3}{|c|}{ Session Chair/Rapporteur } \\
\hline \multirow{4}{*}{1} & \multirow{4}{*}{ Hawaii, USA } & \multirow{4}{*}{ 7-9 March 2001} & \multirow{3}{*}{\multicolumn{2}{|c|}{$\begin{array}{l}\text { MH Properties } \\
\text { Tsutomu Uchida (National Institute of Advanced } \\
\text { Industrial Science and Technologies (AIST)) }\end{array}$}} & \\
\hline & & & & & John A. Ripmeester (National Research \\
\hline & & & & & \\
\hline & & & \multicolumn{2}{|l|}{$\begin{array}{l}\text { Recovery and Sequestration of Hydrates on the Sea Floor } \\
\text { Izuo Aya (Ship Research Institute) }\end{array}$} & Craig Lewis (Chevron) \\
\hline 2 & $\begin{array}{l}\text { Washington, } \\
\text { DC, USA }\end{array}$ & 29-31 October 2002 & \multicolumn{2}{|l|}{$\begin{array}{l}\text { Kinetics of Hydrate Formation and Dissociation } \\
\text { John A. Ripmeester (NRC) }\end{array}$} & P. Raj Bishnoi (University of Calgary) \\
\hline 3 & $\begin{array}{l}\text { Vina der Mar, } \\
\text { Chili }\end{array}$ & 18-21 November 2003 & MH Biokinetics and Dissociation & Tsutomu Uchida (AIST) & Stephen M. Masutani (University of Hawaii) \\
\hline \multirow{2}{*}{4} & \multirow{2}{*}{$\begin{array}{l}\text { Victoria, } \\
\text { Canada }\end{array}$} & \multirow{2}{*}{ 9-11 May 2005} & \multicolumn{2}{|l|}{ MHs Kinetics, Dissociation and Biogeochemistry } & \\
\hline & & & \multicolumn{2}{|l|}{ John A. Ripmeester (NRC) } & $\begin{array}{l}\text { E. Dendy Sloan, Jr. (Colorado School of } \\
\text { Mines (CSM)) }\end{array}$ \\
\hline 5 & $\begin{array}{l}\text { Edinburgh, } \\
\text { Scotland }\end{array}$ & 9-12 October 2006 & \multicolumn{2}{|c|}{$\begin{array}{l}\text { Physical Properties, Modelling \& lab-scale Investigations } \\
\text { Ben Clennell (Commonwealth Scientific and Industrial Research Organisation (CSIRO)) }\end{array}$} & \\
\hline 6 & $\begin{array}{l}\text { Bergen, } \\
\text { Norway }\end{array}$ & 13-15 May 2008 & \multicolumn{2}{|l|}{$\begin{array}{l}\text { Laboratory and pilot scale experiments } \\
\text { James Howard (Conocophilipps) }\end{array}$} & \\
\hline \multirow{2}{*}{7} & \multirow{2}{*}{$\begin{array}{l}\text { Wellington, } \\
\text { New Zealand }\end{array}$} & \multirow{2}{*}{ 10-12 May 2010} & \multicolumn{2}{|l|}{$\begin{array}{l}\text { Production Test and Modelling } \\
\text { George Moridis (Lawrence Berkeley National Laboratory) }\end{array}$} & Takao Inamori (JGI) \\
\hline & & & \multicolumn{2}{|l|}{$\begin{array}{l}\text { Laboratory Studies } \\
\text { Jeffrey Priest (University of Southampton) }\end{array}$} & Dendy Sloan, E., Jr. (CSM) \\
\hline \multirow[t]{2}{*}{8} & \multirow[t]{2}{*}{ Sapporo, Japan } & \multirow[t]{2}{*}{28 May-1 June 2012} & \multicolumn{2}{|l|}{$\begin{array}{l}\text { Industrial Utilization of Gas Hydrate } \\
\text { Kenichi Sano (Mitsui Engineering \& Shipbuilding Co., } \\
\text { Ltd. (MES)) }\end{array}$} & $\begin{array}{l}\text { Yutaek Seo (Korea Advanced Institute of } \\
\text { Science and Technology (KAIST)) }\end{array}$ \\
\hline & & & \multicolumn{2}{|l|}{$\begin{array}{l}\text { Fundamental Hydrate Science Challenges } \\
\text { Yasuhiko Mori (Keio University) }\end{array}$} & Stephen M. Masutani (University of Hawaii) \\
\hline 9 & $\begin{array}{l}\text { Hydrabad, } \\
\text { India }\end{array}$ & 9-13 November 2014 & $\begin{array}{l}\text { Challenges in Producing MHs and When can they be prod } \\
\text { Richard Coffin (Texas A\&M University, Corpus Christi) }\end{array}$ & aced Efficiently \& Safely? & Rajnish Kumar (CSIR-NCL) \\
\hline 10 & Hawaii, USA & 15-17 June 2016 & $\begin{array}{l}\text { Fundamental laboratory and modeling studies } \\
\text { Bjorn Kvamme (University of Bergen) }\end{array}$ & $\begin{array}{l}\text { Werner F. Kuhs } \\
\text { (University Göttingen) }\end{array}$ & Tsutomu Uchida (Hokkaido University) \\
\hline & & & $\begin{array}{l}\text { The Path Forward: Key Areas for Future R\&D } \\
\text { Bjorn Kvamme (University Bergen) }\end{array}$ & $\begin{array}{l}\text { Stephen M. Masutani } \\
\text { (University Hawaii) }\end{array}$ & Tsutomu Uchida (Hokkaido University) \\
\hline
\end{tabular}




\section{Summary of Breakout Sessions}

\subsection{1st Workshop, 2001}

Table 2 [1] shows the breakout sessions at the first Fiery Ice Workshop held in 2001.

Since the late 20th century, natural gas hydrates in ocean sediments and permafrost have been discovered all over the world; e.g., [2], and are recognized as a major unconventional natural gas resource. When the first workshop was held in 2001, researchers were interested primarily in the locations and extent of natural gas hydrate deposits. Phase equilibrium data of gas hydrates was useful to answer these questions. The phase equilibrium conditions had been well investigated by industry [3] since gas hydrates were perceived as an operational nuisance and hazard, and methods were required to inhibit the hydrate formation in gas pipe lines, for example.

Table 2. Breakout sessions (title and chairs/rapporteur).

\begin{tabular}{|c|c|c|}
\hline \multirow{2}{*}{ Number } & \multicolumn{2}{|l|}{ Session Title } \\
\hline & \multicolumn{2}{|l|}{ Session Chair/Rapporteur } \\
\hline 1 & $\begin{array}{l}\text { Methane Hydrate (MH) Properties } \\
\text { Tsutomu Uchida (AIST) }\end{array}$ & John A. Ripmeester (NRC) \\
\hline 2 & $\begin{array}{l}\text { MH Resource Characterization and Distribution } \\
\text { Roy Hyndman (Geological Survey of Canada (GSC), Canada) }\end{array}$ & Roy Hyndman (GSC, Canada) \\
\hline 3 & $\begin{array}{l}\text { Environmental Concerns } \\
\text { Joseph Gettrust (Naval Research Laboratory (NRL-Stennis } \\
\text { Space Center), USA) }\end{array}$ & $\begin{array}{l}\text { Keith T. Matsumoto (PICHTHR, } \\
\text { USA) }\end{array}$ \\
\hline 4 & $\begin{array}{l}\text { Ocean Atmosphere Biosystems } \\
\text { Miriam Kaster (Scripps Inst. Oceanography, USA) }\end{array}$ & Richard B. Coffin (NRL, USA) \\
\hline 5 & $\begin{array}{l}\text { Recovery and Sequestration of Hydrates on the Sea Floor } \\
\text { Izuo Aya (Ship Research Institute) }\end{array}$ & Craig Lewis (Chevron) \\
\hline 6 & $\begin{array}{l}\text { World Energy Framework } \\
\text { Michael Max (Marine Desalination System, USA) }\end{array}$ & Lars Golman (NIVA, Norway) \\
\hline
\end{tabular}

In the MH Properties session, three distinct "streams of interest" were identified as comprising the framework for examining methane hydrate $(\mathrm{MH})$ properties: field studies, laboratory studies, and hydrates for industrial applications. These three areas are described below.

1. Field studies: The thermodynamic model of gas hydrate phase equilibrium conditions [3] was useful to predict potential areas where gas hydrates could exist in the natural environment. Observation and recovery of natural gas hydrate samples were necessary to confirm the existence of these hydrate deposits and to provide key information needed to characterize the reservoirs. The complexity of hydrates required that researchers learn more about the mineralogy and morphology of hydrates and the impact of unknown parameters in the field that could impact stability. These types of factors had not been explored in the hydrate formation and stability research conducted in laboratories at that time. It was suggested that the researchers in the field studies consider the properties on the natural gas hydrates more in detail such as the structures and the interaction with minerals. Also, it was discussed that new tool development was necessary to recover the natural gas hydrate and sediment composites without any disturbances to allow laboratory analysis of gas hydrates under natural conditions.

2. Laboratory studies: To incorporate feedback from the field studies and to accommodate investigations of more complicated systems, researchers conducting laboratory studies were asked to perform experiments using "pure" hydrate samples under well-controlled conditions that would allow clear identification of parameters that control gas hydrate formation. It was recommended that additional phase equilibrium experiments be performed over an expanded range of pressure and temperatures for the purpose of evaluating variability of hydrate composition depending 
on growth conditions. Another study that was suggested was the determination of the rate of conversion of the solid hydrate phase while classifying hydrate morphologies. The importance of research that links measurements of microscopic properties, such as structure and composition, with macroscopic behavior, such as dissociation, for the development of models for nucleation and kinetics, was noted by session participants.

3. Industrial applications: The scaling up of results of laboratory hydrate studies was a primary focus of hydrate research directed toward industrial applications. It was discussed in the session that there was a need to advance hydrate formation technologies to produce large quantities of dense hydrates by controlling kinetics. To solve these challenges, a better understanding of heat and mass transport phenomena was required.

While discussions in the MH Properties session centered around the relation between laboratory studies and plant-scale studies, industrial application issues were primarily reviewed and debated in the Recovery and Sequestration of Hydrates on the Sea Floor session. It was remarked that industry was largely sitting on the sidelines with regard to efforts to advance gas hydrate applications, because the associated economics were uncertain. Therefore, it was concluded that governments needed to take a leading role in order to tap this resource in the next 20 years.

Overall, two main recommendations were made in the breakout sessions of the 1st Workshop:

1. Establish an international database for scientific and technical information on hydrates; researchers and industrial stakeholders should share responsibility in the creation and management of this database.

2. Establish cross-disciplinary forums where empiricists, modelers, laboratory experimentalists, and others can interact.

These recommendations were the first attempt to unite vast and variable fundamental property data on gas hydrates collected under different conditions and by different methods. As a possible way to organize the data, it was suggested that the database be keyed to modelling issues.

\subsection{2nd Workshop, 2002}

Almost one and a half years after the 1st Workshop, the 2nd Fiery Ice Workshop was held in Washington, DC, USA. The breakout sessions of the workshop are listed in Table 3 [4].

Table 3. Breakout sessions (title and chairs/rapporteur).

\begin{tabular}{|c|c|c|}
\hline \multirow{2}{*}{ Number } & \multicolumn{2}{|c|}{ Session Title } \\
\hline & \multicolumn{2}{|c|}{ Session Chair/Rapporteur } \\
\hline 1 & $\begin{array}{l}\text { MH Resource Characterization and Distribution } \\
\text { J.F. Gettrust (NRL, USA) }\end{array}$ & Manabu Tanahashi (AIST) \\
\hline 2 & $\begin{array}{l}\text { Biological Influence on Hydrate Formation, Stability, Con } \\
\text { Miriam Kaster (Scripps Institute of Oceanography, USA) }\end{array}$ & $\begin{array}{l}\text { tent and Lattice Saturation } \\
\text { R. Rogers (Mississippi State University, USA) }\end{array}$ \\
\hline 3 & $\begin{array}{l}\text { Kinetics of Hydrate Formation and Dissociation } \\
\text { John. A. Ripmeester (NRC, Ottawa, Canada) }\end{array}$ & P. Raj Bishnoi (University of Calgary, AB, Canada) \\
\hline 4 & $\begin{array}{l}\text { Environmental Concern: Seabed Stability and Ecosystem } \\
\text { Ryo Matsumoto (University of Tokyo, Japan) }\end{array}$ & $\begin{array}{l}\text { Health } \\
\text { Charles Paull (MBARI, USA) }\end{array}$ \\
\hline 5 & $\begin{array}{l}\text { Methane Storage and Shipping } \\
\text { Hitoshi Narita (ONR-IFO, Japan) }\end{array}$ & L. Norman (Halliburton Energy Service, USA) \\
\hline 6 & $\begin{array}{l}\text { International Interdisciplinary Scientific Network } \\
\text { Art Johnson (Hydrate Energy International, USA) }\end{array}$ & Michael Max (Marine Desalination System, USA) \\
\hline
\end{tabular}

In the Kinetics of Hydrate Formation and Dissociation session, 10 researchers presented information on ongoing or planned hydrate fundamental properties research at that point in time (2002). The topics of these presentations were: 
- Dr. Aya: Discussions on dynamic and static conditions in hydrate formation;

- Dr. Yesinowski: Proton nuclear magnetic resonance observation of MH formation in rock samples in a Remotely operated vehicle (ROV)-controlled seafloor laboratory;

- Dr. Uchida: Two-step formation process of methane-propane mixed gas hydrates in batch-type reactors;

- Dr. Okui: Additives' effects on dissociation rates of hydrates;

- Dr. Makogon: Kinetics in gas hydrate production and transport technology;

- Dr. Kirby: Laboratory observations of sI and sII gas-hydrate decomposition using accurate gas flow measurements, X-ray tomography, and cryogenic scanning electron microscopy (SEM);

- Dr. Taylor: Formation studies of MHs with surfactants;

- Dr. Bishnoi: Macroscopic intrinsic kinetic rate models for hydrate formation and decomposition;

- Dr. Ripmeester: The application of NMR (Nuclear Magnetic Resonance) spectroscopy and magnetic resonance micro (MRM) imaging to the study of hydrate processes;

- Prof. Kvamme: Molecular and dynamic simulation of hydrate formation and decomposition processes.

The presentations and discussions identified the following as important area of study:

- Hydrate formation and dissociation mechanisms;

- Validating models of the kinetics of formation and decomposition;

- How properties and kinetics of hydrates respond to the surrounding environment;

- Nucleation studies at molecular level including the role of sediment mineralogy and bio-surfactants;

- Kinetic submodels that can be incorporated into reservoir simulations or gas production models.

For the most part, the different breakout session outcomes tended to reconfirm recommendations made in the first workshop; e.g., the importance of international collaborations to elevate the level of basic hydrate science research.

\subsection{3rd Workshop, 2003}

For the 3rd Fiery Ice Workshop, four sessions were scheduled to discuss specific topics, but they were not conducted as breakout sessions. Table 4 describes the four sessions [5].

Table 4. Specific Sessions (title and chairs/rapporteur).

\begin{tabular}{clc}
\hline \multirow{2}{*}{ Number } & \multicolumn{1}{c}{ Session Title } \\
\cline { 2 - 3 } 1 & $\begin{array}{l}\text { MH Resource Characterization and Distribution } \\
\text { Juan Diaz Naveas (Universidad Catolica de Valparaiso) }\end{array}$ \\
\hline \multirow{2}{*}{2} & $\begin{array}{l}\text { MH Biokinetics and Dissociation } \\
\text { Bjorn Kvamme (University of Bergen) }\end{array}$ & Tsutomu Uchida (AIST) \\
\hline \multirow{2}{*}{3} & $\begin{array}{l}\text { Environmental Concern: Seabed Stability and Ecosystem Health } \\
\text { (Unclear) }\end{array}$ \\
\hline \multirow{2}{*}{4} & $\begin{array}{l}\text { MH Future Development (Panel discussion) } \\
\text { Arthur Johnson (Hydrate Energy Institute) }\end{array}$ \\
\hline
\end{tabular}

During the MH Biokinetics and Dissociation session, discussions on the following six topics related to hydrate fundamental properties were initiated by the named participants:

- Dr. Shirota: Dissociation properties of MH pellets;

- Dr. Okui: Natural gas hydrate dissociation in sediments;

- Dr. Ripmeester: Hydrate kinetics studied using NMR imaging (MRI);

- Prof. Kvamme: Homogeneous nucleation model of $\mathrm{CO}_{2}$ hydrates in solution; 
- Dr. Uchida: Variation of mixed gas hydrate formation in a closed system;

- Dr. Yoza: Microbial $\mathrm{CH}_{4}$ metabolism in sediments.

In the course of these discussions, it was concluded that researchers should endeavor to identify the key parameters of gas hydrate dissociation processes in order to bridge the growing gap between results from field tests and laboratory studies. Toward this end, the session participants again suggested constructing a database linked to model development issues. Regarding the construction of this database, it was further suggested that standards for the quality of the included results and feasibility of the procedures should be determined via international consensus.

\subsection{4th Workshop, 2005}

The breakout sessions held during the 4th Fiery Ice Workshop are listed in Table 5 [6].

Table 5. Breakout sessions (title and chairs/rapporteur).

\begin{tabular}{clc}
\hline \multirow{2}{*}{ Number } & \multicolumn{1}{c}{ Session Title } \\
\cline { 2 - 3 } 1 & \multicolumn{1}{c}{ Session Chair/Rapporteur } \\
\hline \multirow{2}{*}{2} & $\begin{array}{l}\text { MH Resource Characterization and Distribution: Knowledge Gaps and Barriers in Hydrate Research } \\
\text { Warren Wood (NRL) }\end{array}$ & $\begin{array}{l}\text { MHs Kinetics, Dissociation and Biogeochemistry } \\
\text { John A. Ripmeester (NRC, Ottawa, ON, Canada) }\end{array} \quad$ E. Dendy Sloan (CSM) \\
\hline 3 & $\begin{array}{l}\text { Environmental Concerns: Seabed Stability and Ecosystem Health } \\
\text { Rick Colwell (Idaho National Laboratory (INL)) }\end{array}$ \\
\hline 4 & $\begin{array}{l}\text { MH Future Development } \\
\text { Art Johnson (Hydrate Energy International, USA) }\end{array}$ \\
\hline 5 & $\begin{array}{l}\text { Discussions Between Sessions 1 \& 4 } \\
\text { Warren Wood (NRL) }\end{array}$ \\
\hline \multirow{2}{*}{6} & $\begin{array}{l}\text { Discussions Between Sessions 2 \& 3 } \\
\text { J. A. Ripmeester (NRC, Ottawa, ON, Canada) }\end{array} \quad$ Rick Colwell (INL) \\
\hline
\end{tabular}

In the MHs Kinetics, Dissociation, and Biogeochemistry session, major suggestions were made concerning issues related to the gas hydrate dissociation and formation process. Since Canadian researchers had been a leading force in laboratory investigations of hydrate kinetics (e.g., Bishnoi and co-workers [7-9]), discussions in this session were largely based on their results. On the topic of natural gas hydrate dissociation or gas production processes that were needed to evaluate feasibility of flow assurance or $\mathrm{CO}_{2}$ sequestration, it was pointed out that the effects of minor contaminants, such as higher hydrocarbon gases or electrolytes in the water, on dissociation kinetics or on phase equilibrium conditions, should be examined carefully and precisely. Unfortunately, however, very little work had been performed at that time on elementary kinetic processes such as nucleation statistics, growth rate determination parameters, and mechanisms of hydrate inhibition. As the discussions progressed, it became apparent that there was a large knowledge gap between the available experimental results and model predictions. It was concluded that experimental data needed to be provided to modelers in order to validate the kinetic models and gain necessary insight into kinetic behavior extending from the molecular scale to the macroscopic level.

Research on related biogeochemical topics was also discussed in the context of the MH system as part of the global methane cycle. Knowledge of gas hydrate fundamental properties was useful and necessary to understand the formation, accumulation, and dissociation processes of natural gas hydrates in the natural environment. It was stated that a need existed to study: (1) biosystems in the upper level of the sea floor to better understand natural gas hydrate deposits; (2) the role of MHs on the global climate; and (3) the origin of deep sediment reservoirs of MHs. 
During the breakout sessions, a number of international research collaboration activities were introduced, including an announcement that the international database had been constructed on the CODATA website in order to link the experimental results with the models [10-13].

\subsection{5th Workshop, 2006}

Table 6 lists the breakout sessions for the 5th Fiery Ice Workshop [14]. Due to a lack of information in the Workshop Report, several session chairs and rapporteurs are missing in the table.

Table 6. Breakout sessions (title and chairs/rapporteur).

\begin{tabular}{cll}
\hline \multirow{2}{*}{ Number } & \multicolumn{1}{c}{ Session Title } \\
\cline { 2 - 3 } 1 & \multicolumn{1}{c}{\begin{tabular}{c}
\multicolumn{1}{c}{ Session Chair/Rapporteur } \\
Exploration, Mapping and Characterization \\
Graham Westbrook (Univ. Birmingham)
\end{tabular}} \\
\hline 2 & $\begin{array}{l}\text { MH and Geohazards } \\
\text { (Unclear) }\end{array}$ & (Unclear) \\
\hline 3 & $\begin{array}{l}\text { Physical Properties, Modelling \& Lab-scale Investigations } \\
\text { Ben Clennell (CSIRO Petroleum, Perth, Australia) }\end{array}$ \\
\hline 4 & $\begin{array}{l}\text { MH as an Energy Source } \\
\text { Yoshihiro Masuda (Univ. Tokyo, Japan) }\end{array}$ & Lewis Norman (Halliburton, UK) \\
\hline 5 & $\begin{array}{l}\text { Seafloor Methane Flux and Climate Change } \\
\text { (Unclear) }\end{array}$ & (Unclear) \\
\hline
\end{tabular}

During the Physical Properties, Modelling and Lab-scale Investigations breakout session, discussions focused on two topics: (1) things to remember when conducting laboratory experiments when results are to be applied to model validation; and comparisons with field studies; and (2) limitations of experimental designs simulating field-scale activities and the use of synthetic gas hydrate samples.

It was emphasized that researchers should be aware of the interplay between field and laboratory data and models. Data are necessary to calibrate and validate models and, in turn, models can be applied to interpret the results of laboratory experiments and to help to analyze samples from the field and field logs. Correctly formulated, scaled, and parameterized models depend on the availability of appropriate, high-quality experimental data. It was noted, however, that it was difficult to design up-scaled experiments properly because of uncontrollable factors such as different levels of gas hydrate maturation in synthesized or collected natural samples, and their diverse microstructures. Consequently, participants recommended that priority should be assigned to the development of instruments that could perform in-situ measurements of physical properties of hydrates in the bore hole; e.g., in-situ strength measurement, Cone Penetration Testing (CPT) [15], and downhole NMR [16].

Discussions on the limitations of experimental designs and synthetic gas hydrate samples concluded that direct measurement of essential parameters such as sediment types and stress and strain conditions should be pursued during the synthesis of laboratory hydrate samples. For studies involving gas hydrates in complex environments, emphasis should be placed on preparing samples and experiments that match the primary environmental parameters of interest. For instance, when preparing synthetic hydrate samples to study hydrate behavior in sediments, sediment type, relevant stress and strain, and relative permeability of the samples should be fully considered during the design of the experiment and these parameters should be well-documented.

Discussions were also pursued on the topic of how gas hydrate nucleates and grows in sediments of different mineralogy and texture, and how this influences physical properties such as seismic velocities and resistivity. The session participants remarked that these points were also important when formulating models, since there are limitations on the applicability of laboratory-scale data to the analysis and interpretation of field results. Utilizing collected natural gas hydrate samples instead of synthetic hydrates in laboratory experiments was proposed as a possible solution to overcome 
these limitations; however, it was observed that gas hydrate samples collected in field studies do not necessarily retain their in-situ properties as they may transform when being transferred and stored.

\subsection{6th Workshop, 2008}

The breakout sessions of the 6th Fiery Ice Workshop are shown in Table 7 [17]. Figure 1 is a photograph taken during the general session of that workshop.

Table 7. Breakout sessions (title and chairs/rapporteur).

\begin{tabular}{cl}
\hline \multirow{2}{*}{ Number } & \multicolumn{1}{c}{ Session Title } \\
\cline { 2 - 2 } 1 & $\begin{array}{l}\text { Cession Chair/Rapporteur } \\
\text { Warren Wood (NRL) }\end{array}$ \\
\hline 2 & $\begin{array}{l}\text { MH Fluxes from the Ocean and Potential Climate Implications } \\
\text { Jens Greinert (Renard Center of Marine Geology, Univ. Ghent) }\end{array}$ \\
\hline 3 & $\begin{array}{l}\text { Laboratory and Pilot Scale Experiments } \\
\text { James Howard (Conocophillips) }\end{array}$ \\
\hline 4 & $\begin{array}{l}\text { Characterization and Quantification of Arctic Hydrates } \\
\text { Thomas Lorenson (United States Geological Survey (USGS)) }\end{array}$ \\
\hline 5 & $\begin{array}{l}\text { Exploitation Strategies and Technical Challenges } \\
\text { Koji Yamamoto (Japan Oil, Gas and Metals National Corporation (JOGMEC)) }\end{array}$ \\
\hline 6 & $\begin{array}{l}\text { Theoretical Modeling } \\
\text { Gerard Nihous (Univ. Hawaii) }\end{array}$ \\
\hline
\end{tabular}

In the Laboratory and Pilot Scale Experiments session, the following topics were discussed:

- Is it possible to design laboratory experiments that can accurately simulate the properties of real systems that have developed over geological timescales?

- Available monitoring techniques and corresponding limitations;

- Whether there is a need for controlled, pilot scale experiments employing artificially constructed hydrate formations and, if so, then how should these formations be constructed?

- Can laboratory and pilot scale investigations provide sufficient information for the development of viable hydrate exploitation technologies and strategies to address special Arctic challenges?

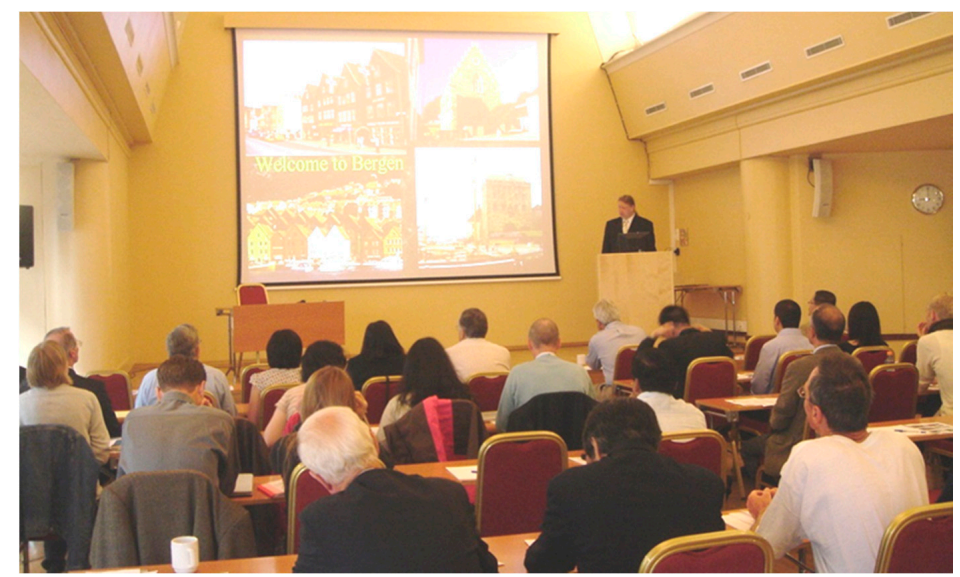

Figure 1. Scene from general session of the sixth Fiery Ice Workshop.

In past workshops, the focus of discussions on fundamental properties of hydrates was the need to construct a database comprising laboratory and field data that could be applied to model development. Toward this end, however, merely creating a database was not sufficient. For the 6th 
workshop, emphasis was placed on acquiring scalable data. In other words, it was more important to obtain data that could simulate a system by using scale factors than try to design experiments and create hydrate samples that perfectly replicate field conditions, since there were intrinsic gaps between laboratory, pilot, and field scale experiments. The intrinsic gaps represent critical differences between laboratory, pilot, and field scale experiments; for instance, differences in homogenous and heterogeneous samples, different sizes of the system, and differences in engineering time frames and geological time frames to form a system.

In the Theoretical Modeling breakout session, the following four topics were identified as key areas of focus of $\mathrm{MH}$ production and science:

1. Rock physics

2. Flow (reservoir) simulations

3. Geomechanical models

4. Environmental models of the fate of released $\mathrm{CH}_{4}$

For each topic, the state-of-the-art models were introduced (e.g., [18]), and issues related to the models were discussed. The models consider a wide range of scales, from molecular dynamic simulations to global climate models. It was suggested that reservoir simulators and their sub-models should be developed because of high interest at the time in methane production from hydrate resources. It was again observed that successful development of reservoir simulators and sub-models demands intensive interactions between modelers and experimentalists to quantitatively formulate hydrate dissociation and formation kinetics. It was concluded that molecular simulations would also be worthwhile pursuing in order to determine absolute values of important thermodynamic properties [19,20].

\subsection{7th Workshop, 2010}

Table 8 provides a list of the breakout sessions of the 7th Fiery Ice Workshop [21].

In the Production Tests and Modelling session, both production tests and production models were summarized, and the results of field tests and modeling studies were compared. Although the laboratory data were still difficult to apply directly to validate models due to the associated short test times and small size of the experiments, the production models at that time were largely based on geomechanical or geophysical models (e.g., [18]). It was recommended that laboratory experiments be designed specifically for model validation, and that the models be improved so that they could be applied to investigate and predict the results of production tests accurately.

Table 8. Breakout sessions (title and chairs/rapporteur).

\begin{tabular}{cll}
\hline \multirow{2}{*}{ Number } & \multicolumn{3}{c}{ Session Title } \\
\cline { 2 - 3 } & \multicolumn{3}{c}{ Session Chair/Rapporteur } \\
\hline \multirow{2}{*}{1} & $\begin{array}{l}\text { Pre-Drilling Characterization } \\
\text { Dan McConnell (AOA Geophysics, Houston, Texas) }\end{array}$ & Tatsuo Saeki (JOGMEC) \\
\hline \multirow{2}{*}{2} & $\begin{array}{l}\text { Exploration Drilling and Post-Drilling Characterization } \\
\text { Gary Humphrey (Fugro GeoConsulting, Inc., Huston, Texas) }\end{array}$ & $\begin{array}{l}\text { Pawan Dewangan (National Institute } \\
\text { Oceanography, Goa, India) }\end{array}$ \\
\hline \multirow{2}{*}{3} & $\begin{array}{l}\text { Production Tests and Modelling } \\
\text { George Moridis (Lawrence Berkeley National Laboratory) }\end{array}$ & Takao Inamori (JGI) \\
\hline \multirow{2}{*}{5} & Gas Hydrate Petroleum System & $\begin{array}{l}\text { Kalachand Sain (National Geophysical } \\
\text { Research Institute, Hyderabad, India) }\end{array}$ \\
\hline & Kelly Rose (U.S. Department of Energy (DOE)) & Dendy Sloan (CSM) \\
\hline
\end{tabular}


In the Laboratory Studies breakout session, work on the International Standards for Hydrates Project was introduced [22]. The goal of this project was to compare results on wave velocities and stress-strain properties of synthetic gas hydrates obtained by different laboratories, because these data were important for modelling. It was determined, however, that the data strongly depended on the hydrate sample used in the experiments. Participating laboratories were therefore advised to prepare hydrate samples and measure both wave velocities and stress-strain properties of these samples using identical, standard protocols. The validity of the obtained data was confirmed by comparison with the standard data. While breakout sessions of previous workshops resulted in many fruitful discussions and produced many suggestions, no major collaborative projects between session participants occurred as direct consequence of these discussions and suggestions. This Laboratory Studies breakout session of the 7th Workshop was unique in that research collaboration was proposed, and several session participants subsequently joined the project.

\subsection{8th Workshop, 2012}

The breakout sessions of the eighth Fiery Ice Workshop are listed in Table 9 [23]. Figure 2 is a photograph taken during one of these breakout sessions.

Table 9. Breakout sessions (title and chairs/rapporteur).

\begin{tabular}{clc}
\hline \multirow{2}{*}{ Number } & \multicolumn{1}{c}{ Session Title } \\
\cline { 2 - 3 } 1 & \multicolumn{1}{c}{ Session Chair/Rapporteur } \\
\hline \multirow{2}{*}{2} & $\begin{array}{l}\text { Evaluation of MH Resource Potential } \\
\text { Tatsuya Fujii (JOGMEC, Chiba, Japan) }\end{array}$ & Miko Fohrmann (GNS Sci., Lower Hutt, New Zealand) \\
\hline \multirow{2}{*}{3} & $\begin{array}{l}\text { Environment Impact } \\
\text { Bjorn Kvamme (University of Bergen, Norway) }\end{array}$ & Harald Nesse (Statoil, Norway) \\
\hline \multirow{2}{*}{$\begin{array}{l}\text { Industrial Utilization of Gas Hydrate } \\
\text { Kenichi Sano (MES) }\end{array}$} & $\begin{array}{l}\text { Methane Gas Hydrate Exploitation and Development } \\
\text { Koji Yamamoto (JOGMEC) }\end{array}$ & Scott Dallimore (NRC) \\
\hline \multirow{2}{*}{5} & $\begin{array}{l}\text { Mechanisms of Hydrate Accumulations in Nature } \\
\text { Hideyoshi Yoshioka (AIST) }\end{array}$ & Richard Coffin (NRL) \\
\hline \multirow{2}{*}{6} & $\begin{array}{l}\text { Fundamental Hydrate Science Challenges } \\
\text { Yasuhiko Mori (Keio University) }\end{array}$ & Stephen M. Masutani (University of Hawaii, USA) \\
\hline
\end{tabular}

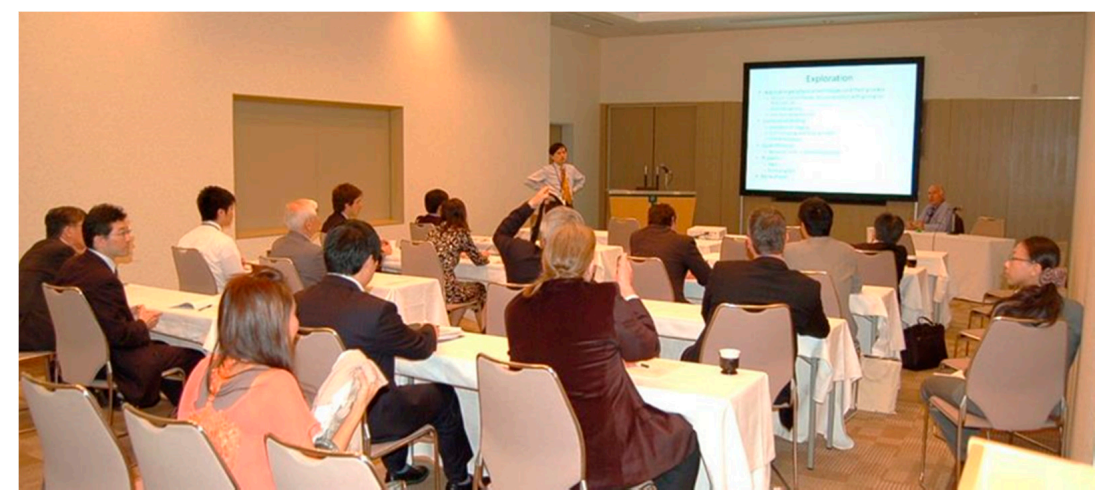

Figure 2. Scene from the breakout session (Methane Gas Hydrate Exploitation and Development) during the eighth Fiery Ice Workshop.

Two unique features of gas hydrates, the self-preservation effect and hydrate guest molecule exchange, were chosen as discussion topics during the Fundamental Hydrate Science Challenges breakout session. The self-preservation effect concerns the ability of gas hydrates to exist at atmospheric pressure at temperatures below the melting point of water ice $(273.2 \mathrm{~K})$, at conditions well outside 
the hydrate thermodynamic stability zone (e.g., [24-28]). Hydrate guest molecule exchange is a phenomenon where the guest molecule in the hydrate crystal can be removed and a different molecule can be substituted in its place. This process can be applied to produce natural gas from $\mathrm{MH}$ and sequesters $\mathrm{CO}_{2}$ simultaneously (e.g., [29-31]). Although the mechanisms of self-preservation and guest molecule exchange were still under investigation at the time, it was debated whether these features could be reliably applied to certain engineering applications.

Dr. S. Takeya (AIST) presented a brief overview of the self-preservation effect $[27,32]$ and the common understanding about the effect at the time were summarized as follows:

- The structure of ice formed around the sample plays a role in self-preservation $[26,28,32]$.

- Self-preservation is observed in the context of natural occurrence of hydrates, such as permafrost. Examination of the permafrost conditions may be the key to explain the mechanism of the self-preservation effect.

- The detailed mechanism of self-preservation effect is still unclear.

To answer the primary question whether the self-preservation effect is a state of quasi-equilibrium or a kinetic phenomenon, it was necessary to compare results from studies which utilize different methods, conditions, and protocols before beginning to posit the underlying mechanism(s) of self-preservation. In addition, the question of whether self-preservation could be reliably applied to certain engineering applications, given the level of understanding of the underlying mechanism at that time, was posed. This issue was discussed in the Industrial Utilization of Gas Hydrate breakout session in more detail; however, a clear consensus was not reached. It was concluded that institutions researching hydrate self-preservation should aggressively publish their findings in international journals to share information about the self-preservation effect under various conditions.

With regard to the hydrate guest molecule exchange process, there was agreement that this is not a solid-state diffusion process, but likely involves destruction of the hydrate lattice and subsequent reformation (e.g., [33]). It was also agreed that it was very difficult to confirm the mechanism using techniques available at the time, since the critical length and time scales were very small. Although $\mathrm{CO}_{2}$ injection into hydrate reservoirs had been validated as a means to produce (release) $\mathrm{CH}_{4}$ gas, there were still large spatial and temporal gaps between laboratory level knowledge and field scale predictions. It was proposed that if the $\mathrm{CO}_{2}-\mathrm{CH}_{4}$ guest molecule exchange was conceptualized as comprising consecutive dissociation and reformation steps, then the process could be modeled accordingly using available, corresponding results on crystal dissociation and formation [30,31].

\subsection{9 th Workshop, 2014}

The breakout sessions of the ninth Fiery Ice Workshop are listed in Table 10 [34].

Table 10. Breakout sessions (title and chairs/rapporteur).

\begin{tabular}{|c|c|}
\hline \multirow{2}{*}{ Number } & Session Title \\
\hline & Session Chair/Rapporteur \\
\hline \multirow{2}{*}{1} & Challenges in Producing MHs and When Can They Be Produced Efficiently \& Safely? \\
\hline & Richard Coffin (Texas A\&M University, Corpus Christi) ～Rajnish Kumar (CSIR-NCL) \\
\hline \multirow[b]{2}{*}{2} & Resource Assessment of MHs and Key Parameters for Drilling \\
\hline & Jun Matsushima (University of Tokyo) \\
\hline \multirow{2}{*}{3} & MHs System: Origin of MH Reservoir \\
\hline & Shyam Chand (University of Tromso) \\
\hline \multirow{2}{*}{4} & MHs Related Geohazards: Slope Stability \& Climate Change \\
\hline & Pawan Dewangan (National Institute Oceanography, India) \\
\hline \multirow{2}{*}{5} & MHs in Sand and Clay Reservoirs, and Their Response to Geo-science Data \\
\hline & Tetsuya Fujii (JOGMEC) $\quad$ Maheswar OJha (CSIR-NGRI, Hyderabad) \\
\hline \multirow{2}{*}{6} & Multidisciplinary Approach for Linking Subsurface Fluid Flow and Gas Hydrates \\
\hline & Aninda Mazumdar (National Institute Oceanography, India) \\
\hline
\end{tabular}


As shown in Table 10, none of the breakout sessions were directly related to fundamental properties of gas hydrates. The most relevant session to this topic, Challenges in Producing MHs and When Can They Be Produced Efficiently \& Safely?, is summarized below.

In this breakout session, three different strategies to extract methane from marine gas hydrates were discussed:

1. Exchange with $\mathrm{CO}_{2}$;

2. Thermal stimulation; and

3. Depressurization.

It was pointed out that one of the major benefits of the $\mathrm{CO}_{2}-\mathrm{CH}_{4}$ exchange method was the associated greenhouse gas sequestration [29]; however, there were still technical challenges and a lack of data that could be used for model validation. Additionally, it was noted that studies of the environmental impacts of this method needed to be performed.

Thermal stimulation employing hot water did not appear to be a feasible option to produce methane from natural gas hydrates, although this method was used once in a field test, i.e., the Mallik project [35]. A consensus was that thermal stimulation has much lower energy efficiency and commercial viability compared to other techniques, especially the depressurization method. Other unconventional thermal stimulation methods were discussed such as catalytic oxidation [36] or in-situ electrical heating methods [37]; however, it was pointed out that these creative methods required additional study and validation before industry could consider the methods as viable options.

Depressurization was then, and remains the favored strategy to extract methane from marine gas hydrates [38]. It was noted, however, that successful long-duration field tests with a minimum production of 20,000-40,000 $\mathrm{m}^{3}$ of gas per day were necessary to make this approach commercially reasonable. It was also mentioned during the breakout session that ways to manage the sand and water that emerge with methane production needed to be devised; this had been a major challenge during field tests conducted to date.

In the case of $\mathrm{MH}$ deposits found along the Indian coastline [39] which are predominantly clay-based, it was argued that new methods for hydrate dissociation needed to be identified, since the depressurization method had been optimized for extraction of sand layer based $\mathrm{MH}$. Although it is difficult to extract methane from clay-based reservoirs, clay minerals tend to adsorb $\mathrm{CO}_{2}$ very well. Thus, it was concluded that the hydrate guest molecule exchange process might be appropriate for this case.

\subsection{0th Workshop, 2016}

The theme of the tenth Fiery Ice Workshop was "15 years of progress and future directions". The primary objectives of the breakout sessions were to highlight accomplishments and changes in hydrate science and engineering since the first workshop in 2001, and to identify directions for the future. A list of the breakout session is provided in Table 11 [40]. In the following section, we summarize the discussions that occurred during two breakout sessions: Fundamental Laboratory and Modelling Studies and The Path Forward: Key Areas for Future Research and Development (R\&D).

A review of previous breakout sessions on topics related to fundamental properties of gas hydrates [41] was presented by Dr. Uchida at the start of the Fundamental Laboratory and Modelling Studies session. Following that presentation, the status of fundamental laboratory and modelling studies and related issues of current concern were discussed by the 20 session participants. It was agreed that although a significant amount of information about gas hydrates has emerged over the past 15 years from laboratory and field studies, serious knowledge gaps and scale gaps between laboratory, modeling, and field studies continue to persist. The wide range of results, which sometimes contradicts each other, makes it difficult to reconcile all of the information, especially for newcomers to the field. It was emphasized that researchers are obligated to clearly describe the detailed objectives, procedures, and conditions of studies when publishing results in order to eliminate or minimize this confusion. 
Table 11. Breakout sessions (title and chairs/rapporteur).

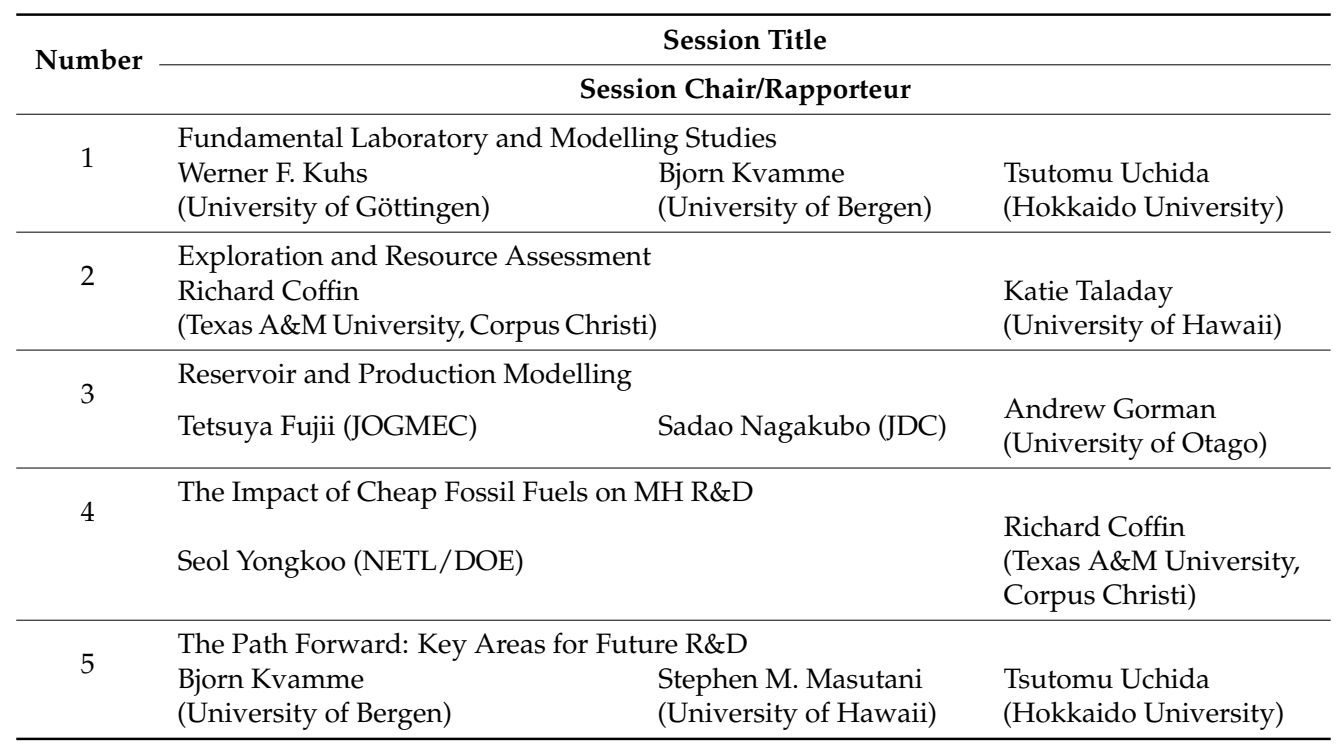

In The Path Forward: Key Areas for Future R\&D breakout session, Dr. Masutani reviewed the progress of MH R\&D and changes in research priorities over the past 15 years. Participants made the point that future progress in MH R\&D depends not only on abstract scientific goals, but is driven strongly by the availability of research funding. Although the level of MH R\&D activity varies widely from country to country, discussions proceeded on the following three themes that many national $\mathrm{MH}$ research programs share.

1. ENVIRONMENT: There was general agreement that natural $\mathrm{MH}$ dissociation is no longer believed to pose a significant threat to global climate. While methane release in the water column and atmosphere continues to be investigated, $\mathrm{MH}$ is peripheral to these studies (e.g., [42]); however, development of technologies to monitor methane leakage into the environment could be an area of growth in the future.

2. SAFETY/GEOHAZARDS: Studies of the relationship between marine MH exploitation and offshore platform stability [43] and of MH formation in pipelines as a potential drilling hazard [43] were suggested as opportunities for future $R \& D$. Research on geotechnical properties of $\mathrm{MH}$ sediments was also expected to remain an important component in the design and construction of subsea-structures.

3. ENERGY DEVELOPMENT: Feasible strategies and methods for gas production from MH deposits have been tested via several successful field experiments over the past 15 years. While results have been generally favorable, gas production from hydrates continues to appear to be expensive and risky. The session participants agreed that fundamental laboratory studies may not be as necessary as they were before; however, some larger scale simulators are useful to examine certain practical issues such as the sanding problem (e.g., [44]). It was concluded that model development continues to be essential, since current models are still unable to accurately predict many important phenomena without significant parameter tuning. Also, it was noted that studies of local environmental impacts of gas production from $\mathrm{MH}$ [42] and public outreach and policy issues need to be pursued if MH exploitation is to proceed successfully.

\section{Discussion}

For several decades, the development of natural MHs as unconventional energy resources has attracted attention in a number countries across the world. The Fiery Ice Workshop was conceived and implemented to serve as an international forum for exchange of information about the various national 
projects. It also promoted international R\&D collaborations in areas of common interest. Incorporation of breakout sessions into the workshop format was undertaken to provide an informal venue for open discussions on a range of focus areas.

A review of the breakout sessions on fundamental properties during the past ten workshops revealed several recurring topics:

1. Problems with knowledge and/or scale gaps that exist between laboratory experiments and field studies;

2. Quantitative comparisons of laboratory data obtained by different laboratories and their evaluation methods to construct a database; and

3. Formulation of kinetic properties of gas hydrates to link with modeling.

\subsection{Knowledge and/or Scale Gaps between Laboratory Experiments and Field Studies}

Laboratory studies typically are performed with 'pure' and small-scale systems, under well-controlled conditions, over very short timeframes compared to geological time-scales. Field scale tests, on the other hand, investigate large-scale and longer term phenomena in heterogeneous systems under often uncontrollable conditions. Therefore, it is usually difficult to apply laboratory data directly to interpret the results of field tests. For example, laboratory studies can predict $\mathrm{MH}$ phase equilibrium conditions precisely; however, they cannot predict the heterogeneous distribution of MHs in the field.

To understand the discrepancies between laboratory and field-scale test results, factors such as the presence of salts, properties of sediments, the movement of gases in the sediments, and hydrates' stress-strain behavior, and how they affect phase equilibrium conditions, need to be investigated. This is essential to predict the heterogeneous distribution of MHs in sediments. Toward this end, collaborations and improved exchanges of information were encouraged during the breakout sessions not only between laboratory and field researchers but also between experimentalists and modelers. Field researchers were encouraged to collect and share detailed information on the sediment systems hosting gas hydrate deposits, and laboratory researchers must endeavor to accurately determine fundamental properties of hydrates over a wide range of conditions relevant to natural occurrences. Modelers could facilitate the comparison of the results of laboratory and field studies by performing relevant simulations.

In some of the breakout sessions, the possibility of defining and synthesizing standard "realistically synthetized samples" in the laboratory was discussed. The goal of producing these samples was to utilize them in laboratory experiments to generate data that could be directly applied to interpret results from field tests. After considerable debate, this appeared to be infeasible, since natural hydrates are formed and evolve over a wide range of conditions [22]. As an alternative, it was proposed that natural core samples could be shared and employed in controlled laboratory experiments. Several breakout session participants remarked that core samples of hydrates may not maintain their in-situ properties even when they are collected with a pressure core sampler [45]. Overall, the consensus recommendation was that laboratory researchers should endeavor to conduct experiments using reproducible, well-characterized, and documented hydrate samples, and consider how to link their laboratory data with the results from field tests. Field researchers need to collaborate closely with laboratory researchers to leverage fully the laboratory results and ensure that their respective data sets can be reconciled.

\subsection{Quantitative Comparison of Laboratory Data Obtained by Different Laboratories and Their Evaluation Methods to Construct a Database}

During the breakout sessions, it was repeatedly emphasized that there existed a critical need to develop a system that would allow hydrate researchers to access data obtained from bench and field tests, in order to accelerate the progress of gas hydrate science and engineering. In response to this call 
for action, an attempt was made to construct an international database on hydrates (Committee on Data for Science and Technology (CODATA) hydrate task group [10-13]). It was found that the data from different laboratories vary because the experiments were conducted using different protocols and under different conditions. Since these laboratory data are crucial to interpret field test results, this problem is significant. To standardize the data, the concept of an "international standard hydrate sample" was proposed at the seventh workshop, and a multi-national collaborative effort was initiated. Unfortunately, this project was not successful because the physical properties of international standard hydrate samples were determined to vary widely from laboratory to laboratory [22].

It was noted in the breakout sessions that the large scatter in published laboratory data on hydrate properties might reflect differences in the quality of the samples that were tested, such as the structural homogeneity, impurities, and cage occupancy. In other words, homogeneity of sample is difficult to guarantee even in laboratory experiments. It is imperative, therefore, that the quality of samples tested be carefully verified and documented before data is allowed to be included in the proposed database $[12,13]$. Database maintenance and management strategies were also discussed during the sessions.

To evaluate the quality of results published in papers under consideration for inclusion in the database, the following criteria were proposed.

- Acceptable level of literature review: the paper must demonstrate that the authors are aware of past work in the area by including citations of previous key publications. This would eliminate unnecessarily repetitive results and identify the precise objectives of the study.

- Sufficient information on experiments: it should be possible to replicate results reported in any paper at different laboratories. Consequently, sufficient details of the experimental procedures must be provided so that others could repeat the experiment, if necessary.

- Rigorous peer review: the peer review process is the only means to guarantee the quality of a research paper. All data under consideration for inclusion in the database must have undergone peer review. Toward this end, senior researchers in the area are encouraged to participate in these peer reviews.

\subsection{Formulation of Kinetic Properties of Gas Hydrates to Link with Modeling}

Attempts to elucidate the mechanisms of hydrate formation and dissociation processes have been made since the late 20th century (e.g., [7-9]). It is generally accepted that formation entails initial nucleation followed by crystal growth. The latter process has been well investigated and formulated; e.g., the growth rate of hydrate crystals depends on the driving force estimated from the experimental conditions $[7,8]$. Nucleation and dissociation processes are not well understood, however, since these processes are considered as partly stochastic phenomena [46] that strongly depend on the experimental system. Therefore, a comprehensive kinetic mechanism of MH crystallization and dissociation is not yet understood sufficiently for application in models.

A working knowledge of nucleation processes is necessary for petroleum and natural gas pipeline flow assurance activities or $\mathrm{CO}_{2}$ hydrate sequestration. Dissociation processes are relevant to production modelling of natural gas from gas hydrate reservoirs. Breakout session participants concurred that these important topics warrant additional modelling and laboratory investigations.

\section{Conclusions}

When the first Fiery Ice Workshop was held in 2001, projects to produce methane gas from natural gas hydrates had just begun. After 15 years, these gas production projects have progressed to field production tests. Fundamental studies of the properties of gas hydrates have undoubtedly played an important role in moving these projects forward. In this paper, we reviewed the discussions that took place in breakout sessions on topics related to fundamental hydrate properties during the past ten workshops, with the objective of reflecting on challenges over the years, changing priorities, and the 
progress that has been made in the area. We also offer some insight into possible future R\&D direction as seen through the eyes of leading researchers in the field.

As is the case in almost all scientific areas of endeavor, studies of hydrate fundamental properties suffer, to a degree, from a lack of access to data collected by various groups in different countries, and variations in the results from supposedly similar experiments due to differences in materials and methods. Discrepancies between the results of bench and field tests reflect not only scale issues, but also the sensitivity of the hydrate system to numerous and complicated factors such as structural inhomogeneities, impurities, and history. During the breakout sessions, a number of collaborative efforts were proposed that might help mitigate these problems, but success to date has been limited.

It was the consensus of workshop participants that gas hydrate R\&D will continue to progress quickly in the near term, and that models should soon be able to provide reliable estimates of the production rates of natural gas from the gas hydrate reservoirs and that a host of practical hydrate applications will emerge, such as the storage and transportation of natural gas.

Acknowledgments: Fiery Ice Workshop has been supported by various foundations; especially the Office of Naval Research Global, the Department of Energy, National Energy Technology Laboratory, the University of Hawai'i, the University of Bergen, National Institute of Advanced Industrial Science and Technology (AIST), and Hokkaido University. A part of contents was reviewed by W. F. Kuhs. We appreciate contributions of all session chairs, rapporteurs, and all local organizing committee members.

Author Contributions: Tsutomu Uchida, Bjørn Kvamme, Richard B. Coffin, Norio Tenma, Ai Oyama and Stephene M. Masutani collected information; Tsutomu Uchida, Bjørn Kvamme, Richard B. Coffin and Stephene M. Masutani summarized the comments; Tsutomu Uchida, Stephene M. Masutani, and Ai Oyama wrote the paper.

Conflicts of Interest: The authors declare no conflict of interest. The founding sponsors had no role in the design of the study; in the collection, analyses, or interpretation of data; in the writing of the manuscript, and in the decision to publish the results.

\section{References}

1. Masutani, S.M.; Coffin, R.B. Final report of Fiery Ice from the Seas. In Proceedings of the 1st Workshop of the International Conference Methane Hydrates, Honolulu, HI, USA, 7-9 March 2001.

2. Kvenvolden, K.A. Methane Hydrate-A major reservoir of carbon in the shallow geosphere? Chem. Geol. 1988, 71, 41-51. [CrossRef]

3. Sloan, E.D.; Koh, C.A. Clathrate Hydrates of Natural Gases, 3rd ed.; CRC Press: Boca Raton, FL, USA, 2008; p. 721.

4. Coffin, R.B.; Masutani, S.M.; Uchida, T.; Kvamme, B. Fiery Ice from the Seas. In Proceedings of the 2nd International Workshop on Methane Hydrate R\&D, Washington, DC, USA, 29-31 October 2002.

5. Universidad Catolica de Valparaiso. Final report of 3rd International Methane Hydrate Workshop on R\&D. In Proceedings of 3rd International Methane Hydrate Workshop on R\&D, Viña del Mar, Chili, 18-21 November 2003.

6. Coffin, R.B.; Chapman, R. Final Report of 4th International Workshop on Methane Hydrate R\&D. In Proceedings of 4th International Workshop on Methane Hydrate R\&D, Victria, BC, Canada, 9-11 May 2005.

7. Bishnoi, P.R.; Natarajan, V. Formation and decomposition of gas hydrates. Fluid Phase Equilib. 1996, 117, 168-177. [CrossRef]

8. Englezos, P.; Kalogerakis, N.; Bishnoi, P.R. Formation and decomposition of gas hydrates of natural gas components. J. Incl. Phenom. Mol. Recognit. Chem. 1990, 8, 89-101. [CrossRef]

9. Kim, H.C.; Bishnoi, P.R.; Heidemann, R.A.; Rizvi, S.S.H. Kinetics of methane hydrate decomposition. Chem. Eng. Sci. 1987, 42, 1645-1653. [CrossRef]

10. Clathrate Hydrate Physical Property Database. Available online: http://gashydrates.nist.gov/ (accessed on 21 April 2017).

11. Uchida, T.; Ripmeester, J.A.; Masutani, S.M.; Sloan, E.D., Jr. Database on the Hydrate Properties: The Influence of Kinetic and Thermodynamic Parameters on Formation and Stability. In Proceedings of the 4th International Conference on Gas Hydrates, Yokohama, Japan, 19-23 May 2002; pp. 678-682. 
12. Sloan, D.; Kuznetsov, F.; Lal, K.; Loewner, R.; Makogon, Y.; Moridis, G.; Ripmeester, J.; Royer, J.-J.; Smith, T.; Tohidi, B.; et al. A Hydrate Database: Vital to the Technical Community. Data Sci. J. 2007, 6, GH1-GH5. [CrossRef]

13. Smith, T.; Ripmeester, J.; Sloan, D.; Uchida, T. Gas Hydrate Markup Language: Laboratory Data. Data Sci. J. 2007, 6, GH18-GH24. [CrossRef]

14. Langhorne, N.; Tohidi, B.; Miles, P.; Rees, J.; Long, D.; Westbrook, G. The summary of 5th International Workshop on Methane Hydrate Research \& Development-Identifying the challenges. Proceedings of 5th International Workshop on Methane Hydrate R\&D, Edinburg, UK, 9-12 October 2006.

15. Sultan, N.; Voisset, M.; Marsset, T.; Vernant, A.M.; Cauquili, E.; Colliat, J.L.; Curinier, V. Detection of free gas and gas hydrate based on 3D seismic data and cone penetration testing: An example from the Nigerian Continental Slope. Mar. Geol. 2007, 240, 235-255. [CrossRef]

16. Kleinberg, R.L.; Flaum, C.; Straley, C.; Brewer, P.G.; Malby, G.E.; Pelzer, E.T., III; Frienderich, G.; Yesinowski, J.P. Seafloor nuclear magnetic resonance assay of methane hydrate in sediment and rock. J. Geophys. Res. 2003, 108, 2137. [CrossRef]

17. Kvamme, B.; Uchida, T.; Masutani, S.; Narita, H.; Coffin, R. The summary of 6th International Methane Hydrate Research and Development Workshop. In Proceedings of the 6th International Workshop on Methane Hydrate R\&D, Bergen, Norway, 13-15 May 2008.

18. Kurihara, M.; Ouchi, H.; Inoue, T.; Yonezawa, T.; Masuda, Y.; Dallimore, S.R.; Collett, T.S.; Analysis of the JAPEX/JNOC/GSC. Mallik 5L-38 Gas Hydrate Thermal Production Test through Numerical Simulation. In Scientific Results from the Mallik 2002 Gas Hydrate Production Research Well Program, Mackenzie Delta, Northwest Territories, Canada; Dallimore, S.R., Collett, T., Eds.; Natural Resources Canada: Ottawa, ON, Canada, 2005; p. 139.

19. Kvamme, B.; Tanaka, H. Thermodynamic stability of hydrates for ethylene, ethane and $\mathrm{CO}_{2}$. J. Phys. Chem. 1995, 99, 7114-7119. [CrossRef]

20. Susilo, R.; Alavi, S.; Ripmeester, J.; Englezos, P. Tuning methane content in gas hydrates via thermodynamic modeling and molecular dynamics simulation. Fluid Phase Equilib. 2008, 263, 6-17. [CrossRef]

21. Pecher, I.; Stagpoole, V.; Henrys, S. Report of Workshop. In Proceedings of Workshop of 7th International Workshop on Methane Hydrate R\&D (Fiery Ice 2010), Wellingon, New Zealand, 10-12 May 2010.

22. Waite, W.F.; Santamarina, J.C.; Rydzy, M.; Chong, S.H.; Grozic, J.L.H.; Hester, K.; Howard, J.; Kneafsey, T.J.; Lee, J.Y.; Nakagawa, S.; et al. Inter-laboratory Comparison of Wave Velocity Measurements in a Sand under Hydrate-Bearing and Other Set Conditions. In Proceedings of the 7th International Conference Gas Hydrates (ICGH 2011), Edinburgh, UK, 17-21 July 2011.

23. Fiery Ice International Steering Committee. Final Report of 8th International Workshop on Methane Hydrate Research \& Development Sapporo 2012 (Full Report). In Proceedings of 8th International Workshop on Methane Hydrate R\&D, Sapporo, Japan, 28 May-1 June 2012.

24. Yakushev, V.S.; Istomin, V.A. Gas-hydrates self-preservation effect. In Physics and Chemistry of Ice; Maeno, N., Hondoh, T., Eds.; Hokkaido University Press: Sapporo, Japan, 1992; pp. 136-140.

25. Stern, L.A.; Circone, S.; Kirby, S.H.; Durham, W.B. Anomalous preservation of pure methane hydrate at 1 atm. J. Phys. Chem. B 2001, 105, 1756-1762. [CrossRef]

26. Kuhs, W.F.; Genov, G.; Staykova, D.K.; Hansen, T. Ice perfection and onset of anomalous preservation of gas hydrates. Phys. Chem. Chem. Phys. 2004, 6, 4917-4920. [CrossRef]

27. Takeya, S.; Ripmeester, J.A. Dissciation behavior of clathrate hydrates to ice and dependence on guest molecules. Angew. Chem. Int. Ed. 2008, 47, 1-5. [CrossRef] [PubMed]

28. Uchida, T.; Sakurai, T.; Hondoh, T. Ice-shielding models for self-preservation of gas hydrates. J. Chem. Chem. Eng. 2011, 5, 691-705.

29. Ohgaki, K.; Takano, K.; Sangawa, H.; Matsubara, T.; Nakano, S. Methane exploitation by carbon dioxide from gas hydrates-Phase equilibria for $\mathrm{CO}_{2}-\mathrm{CH}_{4}$ mixte hydrate system. J. Chem. Eng. Jpn. 1996, 29, 478-483. [CrossRef]

30. Kvamme, B.; Graue, A.; Buanes, T.; Kuznetsova, T.; Ersland, G. Storage of $\mathrm{CO}_{2}$ in natural gas hydrate reservoirs and the effect of hydrate as an extra sealing in cold aquifers. Int. J. Greenh. Gas Control 2007, 1, 236-246. [CrossRef]

31. White, M.; McGrail, P. Designing a Pilot-Scale Experiment for the Production of Natural Gas Hydrates and Sequestration of $\mathrm{CO}_{2}$ in Class 1 Hydrate Accumulations. Energy Procedia 2009, 1, 3099-3106. [CrossRef] 
32. Takeya, S.; Ripmeester, J.A. Anomalous preservation of $\mathrm{CH}_{4}$ hydrate and its dependence on the morphology of hexagonal ice. ChemPhysChem 2010, 11, 70-73. [CrossRef] [PubMed]

33. Lee, H.; Seo, Y.; Seo, Y.T.; Moudrakovski, I.L.; Ripmeester, J.A. Recovering Methane from Solid Methane Hydrate with Carbon Dioxide. Angew. Chem. Int. Ed. 2003, 42, 5048-5051. [CrossRef] [PubMed]

34. Gupta, H.K.; Nayak, S.; Talukdar, S.B.N.; Srivastava, S.K.; Bhaskar Rao, Y.J.; Naqvi, S.W.A.; Atmanand, M.A.; Rajan, S.; Kumar, P.; Sain, K. Summary of the Workshop. Proceedings of 9th International Methane Hydrate R\&D (Fiery Ice 2014) Workshop, Hyderabad, India, 10-12 November 2014.

35. Yamamoto, K.; Dallimore, S.R. Aurora-JOGMEC-NRCan Mallik 2006-2008 Gas Hydrate Research Project Progress. In Fire in the Ice, Methane Hydrate Newsletter; National Energy Technology Laboratory: Morgantown, KY, USA, 2008.

36. Shicks, J.M.; Spangenberg, E.; Giese, R.; Steinbauer, B.; Klump, J.; Luzi, M. New Approaches for the Production of Hydrocarbons from Hydrate Bearing Sediments. Energies 2011, 4, 151-172. [CrossRef]

37. Minagawa, H.; Ito, T.; Kimura, S.; Kaneko, H.; Noda, S.; Narita, H. Depressurization and Electrical Heating of Hydrate Sediment for Gas Production. In Proceedings of the 11th Ocean Mining and Gas Hydrate Symposium, Kona, HI, USA, 21-27 June 2015.

38. Kurihara, M.; Sato, A.; Ouchi, H.; Ohbuchi, Y.; Masuda, Y.; Narita, H.; Ebinuma, T.; Saeki, T.; Fujii, T. Examination on gas producibility from Eastern Nankai Trough methane hydrate resources. J. Jpn. Assoc. Pet. Tech. 2009, 74, 311-324. (In Japanese). [CrossRef]

39. Kumer, P.; Collett, T.S.; Vishwanath, K.; Shukla, K.M.; Nagalingam, J.; Lall, M.V.; Yamada, Y.; Schultheiss, P.; Holland, M. Gas Hydrate-Bearing Sand Reservoir Systems in the Offshore of India: Results of the India National Gas Hydrate Program Expedition 02. In Proceedings of the Fiery Ice 2016, Hololulu, HI, USA, 15-17 June 2016.

40. Fiery Ice 2016. Available online: http://www.hnei.hawaii.edu/focus/alternative-fuels/fiery-ice-2016 (accessed on 21 April 2017).

41. Uchida, T.; Kvamme, B.; Coffin, R.; Tenma, N.; Oyama, A.; Masutani, S. Review on "Fundamental Properties" of Gas Hydrates discussed in the Breakout Session of Fiery Ice Workshop. In Proceedings of Fiery Ice 2016, Honolulu, HI, USA, 15-17 June 2016.

42. Masuda, Y.; Uchida, T.; Nagakubo, S.; Satoh, M. Methane hydrates. In Fossil Fuels; World Scientific Series in Current Energy Issues 1; Crawley, G.M., Ed.; World Scientific Publishing Co. Private Ltd.: Singapole, 2016; Chapter 10; pp. 289-327.

43. CBM \& Shale Gas Forum and Gas Hydrate Forum in the Japan Institute of Energy. In Unconventional Hydraet Natural Gases, the New Leaders of Energy Resources: Coal Bed Methane, Shale Gas, and Methane Hydrate; Japan Industrial Publishing Co. Ltd.: Tokyo, Japan, 2014; p. 270. ISBN 4819026089. (In Japanese)

44. Yokoyama, T.; Nakayama, E.; Ono, M.; Hoshino, M.; Saito, H.; Konno, Y.; Nagao, J. Visualization of methane hydrate dissociation process in HiGUMA by using seismic tomography. In Proceedings of the Fiery Ice 2016, Hololulu, HI, USA, 15-17 June 2016.

45. Yamamoto, K. Overview and introduction: Pressure core-sampling and analyses in the 2012-2013 MH21 offshore test of gas production from methane hydrates in the eastern Nankai Trough. Mar. Pet. Geol. 2015, 66, 296-309. [CrossRef]

46. Barlow, T.W.; Haymet, A.D.J. An automated lag-time apparatus for studying the nucleation of supercooled liquids. Rev. Sci. Instrum. 1995, 66, 2996. [CrossRef]

(C) 2017 by the authors. Licensee MDPI, Basel, Switzerland. This article is an open access article distributed under the terms and conditions of the Creative Commons Attribution (CC BY) license (http://creativecommons.org/licenses/by/4.0/). 